\title{
Decalcifying odontocete ears following a routine protocol with $\mathrm{RDO} \circledast$
}

\author{
Maria Morell a , Eduard Degollada ${ }^{a}$, Josep Maria Alonso ${ }^{a}$, Thierry Jauniaux ${ }^{\mathrm{b}}$, Michel André ${ }^{\mathrm{a}, *}$ \\ a Laboratori d'Aplicacions Bioacústiques, Universitat Politècnica de Catalunya, Avda. Rambla Exposició s/n 08800-Vilanova i la Geltrú, Spain \\ b Université de Liège, Place du 20-Aout, 9 à B-4000, Liège, Belgium
}

\section{A R T I C L E I N F O}

\section{Article history:}

Received 5 September 2008

Received in revised form 7 May 2009

Accepted 11 May 2009

\section{Keywords:}

Cetacean

Decalcification protocol

Hydrochloric acid

Noise pollution

Odontocete

Periotic bone

\begin{abstract}
A B S T R A C T
The study of the organ of Corti is essential to assess the impact of underwater noise on cetaceans. While classical histology techniques (including EDTA decalcification) have been previously considered, the process is time consuming. Independently from the histological technique, one of the challenging steps after extraction and fixation of the samples is to decalcify the bone envelope to access the cochlea without damaging the soft tissues. Here, we propose to use a fast commercial decalcifier (RDO®). 93 ears from 11 different odontocetes species stranded in the Mediterranean, Spanish North Atlantic and North Sea were used to precisely determine the decalcification time. Depending on the tympanic-periotic volume of the species, the decalcification time ranged from several hours to a few days, allowing a subsequently faster observation of the cochlear structures through routine microscope techniques.
\end{abstract}

(c) 2009 Elsevier B.V. All rights reserved.

\section{Introduction}

While there is an increasing pressure of human impacts on the oceans, very little is known about the effect of underwater noise on marine organisms. Because of their vital dependence on acoustic information and their role in the food chain as top predators, the study of the effects of noise on cetaceans (Mammalia, Cetacea) has recently become ecologically essential (Richardson et al., 1995). Although some of these effects can be found in organs not directly related to the acoustic pathways (Jepson et al., 2003), other lesions are expected to affect the acoustic pathways, particularly the organ of Corti and its associated hair cells (Lurie et al., 1944). The examination of these structures implies accessing fresh samples and determining possible correlations between a pathological change of cochlea morphology and a sound exposure. Moreover, basic morphological and comparative descriptions of the cetacean ears are still lacking, probably because of the difficulty in obtaining a suitable material, and a reliable protocol for analysis.

A detailed description of the cochlea morphology was presented for Tursiops truncatus (Wever et al., 1971a,b,c) and studies of the basilar membrane and osseus spiral laminae in different odontocete species have been conducted to compare their hearing capabilities (Ketten and Wartzok, 1990; Ketten, 1992, 1994). Nevertheless, much work is still needed to describe the morphology of other species hearing structures.

\footnotetext{
* Corresponding author. Tel.: +34 9389672 27; fax: +34 938967201 E-mail address: michel.andre@upc.edu (M. André).
}

The middle and inner ear are enclosed by the tympanic and periotic bones, respectively, forming the tympanic-periotic (T-P) complex. The T-P complex, which is suspended through ligaments outside the skull in a peribullar cavity, is surrounded by air filled sinuses, allowing the acoustic isolation from the skull (Reysenbach de Haan, 1957; Fleischer, 1976; Ketten and Wartzok, 1990; Nummela et al., 1999b). While some authors expressed doubts about the functionality of the middle ear (Fraser and Purves, 1954; Reysenbach de Haan, 1957; McCormick et al., 1970; Fleisher, 1978; Ridgway et al., 1997) others presented morphological evidences supporting the active role of the middle ear in sound transmission (Nummela et al., 1999a,b; Hemila et al., 1999, 2001; Ketten, 2000; Morell et al., 2007).

Despite of these previous findings in a limited number of cetacean species, little data are available to comparatively describe inner ear structures. Stranding events may represent a unique opportunity to help building knowledge on the morphology of cetacean hearing organs and their potential sensitivity when exposed to noise.

One of the challenging steps after extraction and fixation of the ear samples is to decalcify the very dense bone envelope (T-P complex) to access the cochlea without damaging the soft tissues. While classical histology techniques (including EDTA decalcification) have been previously considered, the process is time consuming (Ketten, 1984). However, a rapid assessment of possible lesions in the Organ of Corti after sound exposure, in addition to allow basic morphological and comparative studies at larger scales, is crucial for decision making when facing a conservation problem.

We chose to use a fast commercial decalcifier (RDO®), based on hydrochloric acid, to shorten the decalcification times observed with other methods. Previous studies compared the effects of $\mathrm{HCl}$ and EDTA on the mouse mandible tissue and concluded that, morphologically, 
Table 1

Total number of ears used for the study to establish the decalcification protocol and to determine the decalcification times for each species.

\begin{tabular}{|c|c|c|c|c|}
\hline Species & Number of ears & Number of animals & Conservat1on state & Protocol \\
\hline Phocoena phocoena & 48 & 27 & $\begin{array}{l}37 \text { ears of state } 2 \\
7 \text { ears of state } 3 \\
4 \text { ears unknown state }\end{array}$ & $\begin{array}{l}\text { Freezing }+ \text { defreezing }+ \\
\text { fixation with } 10 \% \text { formalin }\end{array}$ \\
\hline Tursiopstruncatus & 8 & 8 & $\begin{array}{l}1 \text { ear of state } 1 \\
3 \text { ears of state } 2 \\
2 \text { ears of state } 3 \\
1 \text { ear of state } 5 \\
1 \text { ear unknown state }\end{array}$ & Fixation with $10 \%$ formalin \\
\hline Stenella frontalis & 13 & 7 & $\begin{array}{l}4 \text { ears of state } 2 \\
4 \text { ears of state } 3 \\
4 \text { ears of state } 4 \\
1 \text { ear unknown state }\end{array}$ & Fixation with $10 \%$ formalin \\
\hline Stenella coeruleoalba & 13 & 8 & $\begin{array}{l}5 \text { ears of state } 1 \\
5 \text { ears of state } 2 \\
3 \text { ears of state } 5\end{array}$ & Fixation with $10 \%$ formalin \\
\hline Delphinus delphis & 2 & 2 & $\begin{array}{l}1 \text { ear of state } 2 \\
1 \text { ear of state } 5\end{array}$ & Fixation with $10 \%$ formalin \\
\hline Kogia simus & 2 & 2 & $\begin{array}{l}1 \text { ear of state } 2 \\
1 \text { ear of state } 5\end{array}$ & Fixation with $10 \%$ formalin \\
\hline Kogia breviceps & 2 & 2 & $\begin{array}{l}1 \text { ear of state } 3 \\
1 \text { ear of state } 5\end{array}$ & Fixation with $10 \%$ formalin \\
\hline Steno bredanensis & 2 & 2 & $\begin{array}{l}1 \text { ear of state } 2 \\
1 \text { ear of state } 3\end{array}$ & Fixation with $10 \%$ formalin \\
\hline Lagenodelphis hosei & 1 & 1 & 1 ear of state 2 & Fixation with $10 \%$ formalin \\
\hline Globicephala macrorhynchus & 1 & 1 & 1 ear of state 4 & Fixation with $10 \%$ formalin \\
\hline Globicephala melas & 1 & 1 & 1 ear of unknown state & Fixation with $10 \%$ formalin \\
\hline
\end{tabular}

The preservation state is expressed as a scale from 1 (very fresh) to 5 (autolytic).

both decalcifiers preserved well the cellular structures (Shibata et al., 2000). However, for DNA or RNA studies the use of $\mathrm{HCl}$ for decalcification was not suited, while EDTA gave better results (Alers et al., 1999; Shibata et al., 2000; Moore et al., 2002). Callis and Sterchi (1998), when comparing 25\%, 50\% RDO® and EDTA pH 3.2, 7.0, 10.3 amongst other decalcifier agents, concluded that "all types of decalcification solutions and methods will produce excellent results if carefully watched".

Here, we propose to test the inclusion of $\mathrm{RDO} \otimes$ in a standard protocol that will allow the rapid and direct observation of inner ear structures with microscopy techniques and determine the correlation between the periotic decalcification time and the tympanic-periotic volume.

\section{Materials and methods}

Ninety three (93) ears from 11 different odontocetes species stranded in the Mediterranean Sea, Spanish North Atlantic and North Sea have been extracted. Specifically, the species processed were: Phocoena phocoena $(n=48)$, Stenella coeruleoalba $(n=13)$, Stenella frontalis $(n=13)$, T. truncatus $(n=8)$, Delphinus delphis $(n=2)$, Kogia simus $(n=2)$, Kogia breviceps $(n=2)$, Globicephala macrorhynchus $(n=1)$, Globicephala melas $(n=1)$, Steno bredanensis $(n=2)$ and Lagenodelphis hosei ( $n=1$, Table 2$)$.

After extraction, the samples were fixed with $10 \%$ buffered formaline and used subsequently to precisely determine the decalcification time with different concentrations of RDO®.

All the ears were fixed using this protocol except in three cases:

- 48 P. phocoena ears were frozen and defrosted before being fixed in $10 \%$ buffered formalin

- One S. coeruleoalba ear was fixed in $2.5 \%$ glutaraldehyde with a phosphate buffer $0.1 \mathrm{M}$

- One S. coeruleoalba ear was fixed in $2.5 \%$ glutaraldehyde with $0.5 \%$ paraformaldehyde and a phosphate buffer $0.1 \mathrm{M}$ (Table 1 ).

$\mathrm{RDO}{ }^{\circledR}$ is a rapid decalcifier based on hydrochloric acid (Apex Engineering Products Corporation, Aurora, Illinois, USA). Specifically we tried with $100 \%$ RDO ${ }^{\circ}, 80 \%$ RDO® (diluted with $80 \%$ ethanol), $75 \%$ RDO ${ }^{\circ}$ (diluted with distilled water) and 50\% RDO ${ }^{\circledR}$ (diluted with distilled water and changing the media after $24 \mathrm{~h}$ by or $50 \%$ RDO ${ }^{\circledR}$ or $25 \%$ RDO ${ }^{2}$, also diluted with distilled water).

Because the protocol assumes that there is no need to decalcify completely the periotic bone to access the Organ of Corti cells through scanning electron microscopy (SEM), the analysis was based on the time range necessary to uncover the vestibular scalae and the stria vascularis of the cochlea. This is what we have called the endpoint, which represents, in the frame of this study, the minimum necessary time of decalcification. Therefore, techniques like X-ray observation or chemical tests (e.g. using ammonium oxalate/ammonium hydroxide to precipitate calcium as calcium oxalate) were not used, and a mechanical dissection was necessary to establish the decalcification endpoint.

\section{Results}

Preliminary decalcification experiments were conducted with $100 \%$ RDO ${ }^{\circ}$ on samples from $P$. phocoena ( $29 \%$ of $N=$ total number

Table 2

Decalcification times of the periotic bones analyzed during the study.

\begin{tabular}{|c|c|c|c|c|}
\hline Species & Mean & Min-max & $n$ & $N$ \\
\hline Phocoena phocoena & $26 h 39^{\prime}$ & $26 h-28 h 47^{\prime}$ & 11 & $\overline{48}$ \\
\hline Tursiops truncatus & $66 \mathrm{~h} 48^{\prime}$ & 65 h $51^{\prime}-67$ h $44^{\prime}$ & 2 & 8 \\
\hline Stenella frontalis & $45 \mathrm{~h} 54^{\prime}$ & $41 \mathrm{~h} 40^{\prime}-49 \mathrm{~h} 27^{\prime}$ & 5 & 13 \\
\hline Stenella coeruleoalba & $45 \mathrm{~h} 39^{\prime}$ & 40h $07^{\prime}-49$ h $23^{\prime}$ & 8 & 13 \\
\hline Delphinus delphis & $52 \mathrm{~h} 02^{\prime}$ & & 1 & 2 \\
\hline Kogia simus & $32 \mathrm{~h} 16^{\prime}$ & & 1 & 2 \\
\hline Kogià breviceps & $32 \mathrm{~h} \mathrm{03'}$ & $31 \mathrm{~h} 27^{\prime}-32 \mathrm{~h} 39^{\prime}$ & 2 & \\
\hline Steno bredanensis & $65 \mathrm{~h} 50^{\prime}$ & 59h $13^{\prime}-72 \mathrm{~h} 27^{\prime}$ & 2 & 2 \\
\hline Lagenodelphis hosei & 30h $10^{\prime}$ & & 1 & \\
\hline Globicephala macrorhynchus & $87 \mathrm{~h} 15^{\prime}$ & & 1 & \\
\hline Globicephala melas & $88 \mathrm{~h} 58^{\prime}$ & & 1 & \\
\hline
\end{tabular}

Mean; Min-max, minimum and maximum decalcification time of periotic bones for each species; $n$, number of samples used to determine the final decalcification time, with a $50 \% \mathrm{RDO} \circledast$ and $25 \% \mathrm{RDO} \otimes$ after $24 \mathrm{~h}$ routine protocol; $N$, total number of samples used to establish the decalcification protocol. 


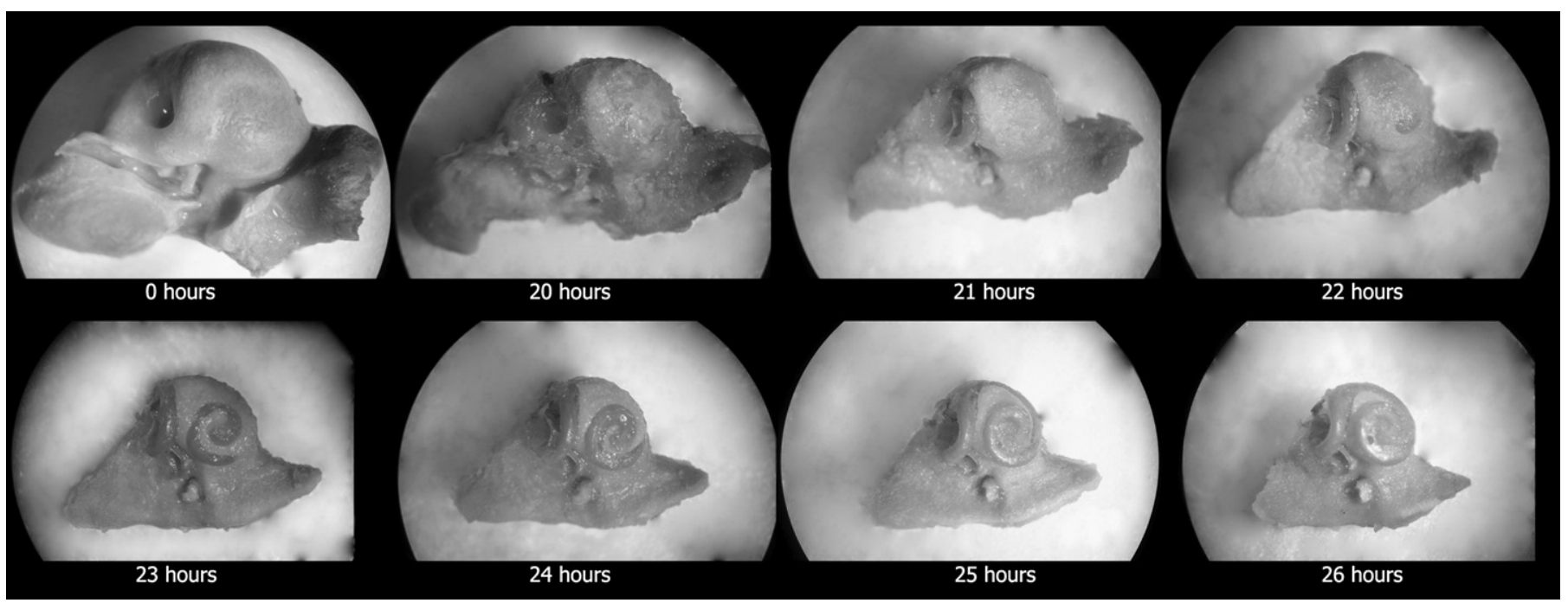

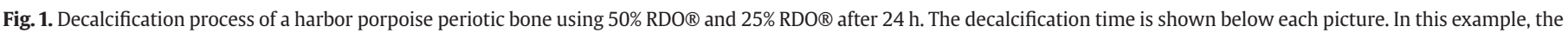
vestibular scalae and the stria vascularis of the cochlea were uncovered after $26 \mathrm{~h}$.

of samples per species, see Table 2), T. truncatus (62\% of $N$ ) and $S$. coeruleoalba $(8 \%$ of $N)$. Despite the fact that decalcification time with this RDO ${ }^{\circledR}$ concentration was considerably reduced (from $68 \%$ to $84 \%$ depending on the species) compared to the results shown below with $50 \%, 75 \%$, and $80 \%$ RDO ${ }^{\circledR}$ concentration, the determination of the endpoint times resulted less accurate thus leading to the possibility of tissue overdecalcification and the introduction of consecutive artefacts.

More accurate decalcifying endpoint times were obtained using $50 \%$ RDO $®$ (diluted with distilled water) and by changing the medium and the concentration (25\% RDO® diluted with distilled water) after $24 \mathrm{~h}$ than with the other dilutions:

- $100 \%$ RDO®

- $80 \%$ RDO® diluted with $80 \%$ ethanol

- 75\% RDO® diluted with distilled water
- 50\% RDO ${ }^{\circledR}$ diluted with distilled water and changing the media after 24 h by $50 \%$ RDO®.

The dilution of $50 \%$ RDO $®$ and $25 \%$ RDO $\AA$ after $24 \mathrm{~h}$, allowed slowing down the decalcification at the end of the process and stopping it accordingly. The decalcification times are shown in Fig. 1.

From the total samples that were analyzed, the mean and the minimum and maximum values of the decalcification time of all species studied following the best decalcification protocol (that was $50 \% \mathrm{RDO} \circledast$ for the first $24 \mathrm{~h}$ and $25 \% \mathrm{RDO} \otimes$ for the rest of the time) is shown in Table 2.

A highly linear correlation is observed comparing the periotic decalcification times with:

- the tympanic-periotic complex volumes extracted from previous CT scans (Morell et al., 2007) ( $r=0.935, n=12$, Fig. 2A) or,
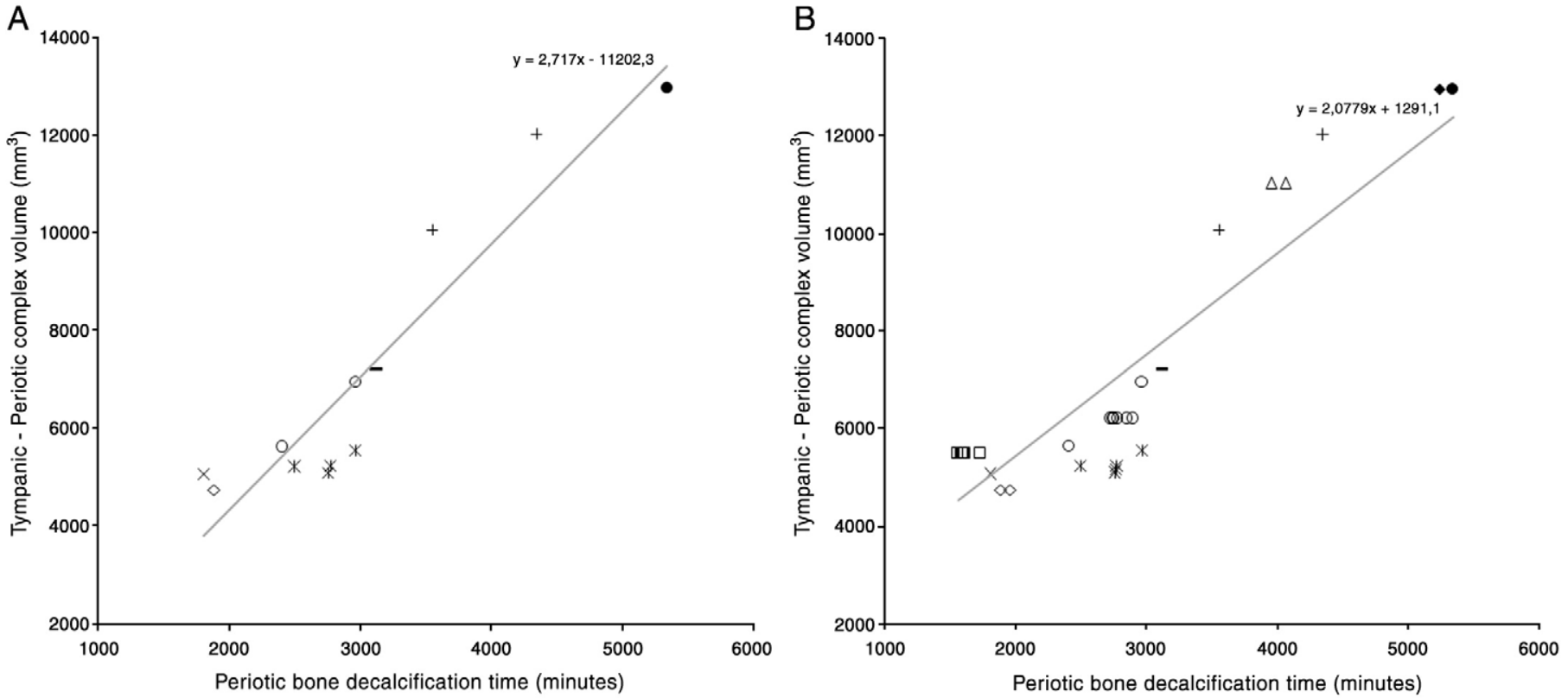

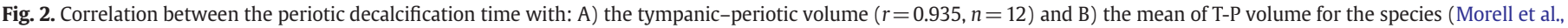

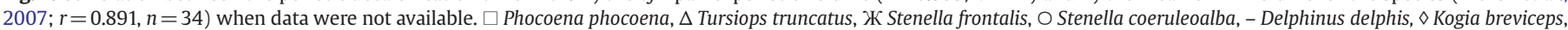
+ Steno bredanensis, $\times$ Lagenodelphis hosei, $\bullet$ Globicephala melas, $\bullet$ Globicephala macrorhynchus. 
- the average of the tympanic-periotic complex volumes for each species (Morell et al., 2007) when data were not available ( $r=0.891, n=34$, Fig. 2B).

The remaining specimens (" $N-n$ " samples in Table 2 ) were used to adjust the protocol (tests with different volumes, changes of media following different periods of time or overdecalcification, all conducting to unusable results) with different RDO® dilutions (100\% RDO®, $50 \% \mathrm{RDO} \otimes$ diluted with distilled water and changing the media after 24 h by $50 \%$ RDO $\circledast$, $75 \%$ RDO $®$ diluted with distilled water and $80 \%$ RDO® diluted with $80 \%$ ethanol).

\section{Discussion and conclusion}

Following a routine protocol with a specific dilution of $\mathrm{RDO} 囚$, the odontocete ear decalcification time ranged from several hours to a few days (Table 2), depending on the volume of the periotic bone, that, in turn, is highly correlated with the T-P complex volume (Morell et al., 2007). This reduced the decalcification time from a few months using EDTA (Ketten, 1984) to a maximum of a week for the largest T-P complexes. The high correlation between the T-P complex bone volume and the periotic decalcification time should allow a better approximation to the accurate decalcification time to analyze odontocete ears in the future (Fig. 2).

The decalcification protocol developed for this study was adjusted to perform an examination of the Organ of Corti's cells through scanning electron microscopy (SEM) and establish a fast diagnosis of possible lesions in fresh material. The respective decalcification time values may need to be increased if a complete decalcification of the periotic bone is needed for routine histology or transmission electron microscopy techniques.

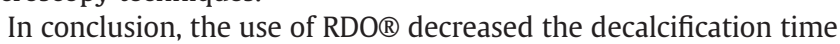
of cetacean ear bones, thus allowing comparative morphological studies with a greater number of samples. Accordingly this method could represent a fast diagnostic tool to analyse possible alterations of the Organ of Corti, for example induced by sound exposure.

\section{Acknowledgements}

We would like to thank the Generalitat de Catalunya, our colleagues and the stranding organizations who helped us in collecting the ears, especially Paco Toledano (PROMAR), Alfredo López and María Llarena (CEMMA), Beatriz González (CRAM), Encarna Gómez (Biologia Animal-Vertebrats, UB), Mardik Leopold (IMARES) and Kees C. J. Camphuysen (Royal NIOZ).

This study was funded by the Spanish Ministry of the Environment under contract 083/SDGTB/2007. [SS]

\section{References}

Alers, J.C., Krijtenburg, P.J., Vissers, K.J., van Dekken, H., 1999. Effect of bone decalcification procedures on DNA in situ hybridization and comparative genomic hybridization: EDTA is highly preferable to a routinely used acid decalcifier. Journal of Histochemistry \& Cytochemistry 47, 703-709.
Callis, G., Sterchi, D., 1998. Decalcification of bone: literature review and practical study of various decalcifying agents, methods, and their effects on bone histology. Journal of Histotechnology 21, 49-58.

Fleischer, G., 1976. Hearing in extinct cetaceans as determined by cochlear structure. Journal of Paleontology 50, 133-152.

Fleischer, G., 1978. Evolutionary of the mammalian middle ear. Advances in Anatomy Embryology, and Cell Biology 55,1-70.

Fraser, F.C., Purves, P.E., 1954. Hearing in cetaceans. Bulletin of the British Museum, Natural History. Zoology 2, 103-116.

Hemila, S., Nummela, S., Reuter, T., 1999. A model of the odontocete middle ear. Hearing Research 133, 82-97.

Hemila, S., Nummela, S., Reuter, T., 2001. Modeling whale audiograms: effects of bone mass on high-frequency hearing. Hearing Research 151, 221-226.

Jepson, P.D., Arbelo, M., Deaville, R., Patterson, I.A.P., Castro, P., Baker, J.R., Degollada, E., Ross, H.M., Herraez, P., Pocknell, A.M., Rodriguez, F., Howie, F.E., Espinosa, A., Reid, R.J., Jaber, J.R., Martin, V., Cunningham, A.A., Fernandez, A., 2003. Gas-bubble lesions in stranded cetaceans - was sonar responsible for a spate of whale deaths after an Atlantic military exercise? Nature 425, 575-576.

Ketten, D.R., 1984. Correlations of Morphology with Frequency for Odontocete Cochlea: Systematics and Topology. The Johns Hopkins University, Baltimore.

Ketten, D.R., 1992. The cetacean ear: form frequency and evolution. 1994 In: Thomas, J.A. Ketten, D.R. (Eds.), Functional Analyses of Whale Ears: Adaptations for Underwater Hearing, Oceans' 94 Proceedings, pp. 264-270.

Ketten, D.R., 1994. Functional analyses of whale ears: adaptations for underwater hearing. Oceans' 94 Proceedings, pp. 264-270.

Ketten, D.R., 2000. Cetacean ears. In: Au, W.W.L., Popper, A.N., Fay, R.R. (Eds.), Hearing by Whales and Dolphins. InSpringer handbook of auditory research, pp. 43-108.

Ketten, D.R., Wartzok, D., 1990. Three-dimensional reconstructions of the dolphin ear In: Thomas, J., Kastelein, R. (Eds.), Sensory Abilities of Cetaceans. InPlenum Press, New York, pp. 81-105

Lurie, M.H., Davis, H., Hawkins Jr, J.E., 1944. Acoustic trauma of the organ of Corti in the guinea pig. Laryngoscope 54, 375-386.

McCormick, J.G., Wever, E.G., Palin, J., Ridgway, S.H., 1970. Sound conduction in the dolphin ear. Journal of the Acoustical Society of America 48, 1418-1428.

Moore, J.L., Aros, M., Steudel, K.G., Cheng, K.C., 2002. Fixation and decalcification of adult zebrafish for histological, immunocytochemical, and genotypic analysis. BioTechniques 32, 296-298.

Morell, M., Degollada, E., van der Schaar, M., Alonso, J.M., Delory, E., López, A., Dewez, A., André, M., 2007. Comparative morphometry of odontocete ears through computerized tomography. Journal of the Marine Biological Association of the United Kingdom 87, 69-76.

Nummela, S., Wagar, T., Hemila, S., Reuter, T., 1999a. Scaling of the cetacean middle ear Hearing Research 133, 71-81.

Nummela, S., Reuter, T., Hemila, S., Holmberg, P., Paukku, P., 1999b. The anatomy of the killer whale middle ear (Orcinus orca). Hearing Research 133, 61-70.

Reysenbach de Haan, F.W., 1957. Hearing in whales. Acta Oto-laryngologica. Supplementum 134, 1-114.

Richardson, W.J., Greene Jr., C.R., Malme, C.I., Thomson, D.H., 1995. Marine Mammals and Noise. Academic Press, San Diego, CA. 576 pp.

Ridgway, S.H., Carder, D.A., Smith, R.R., Kamolnick, T., Elsberry, W.R., 1997. First audiogram for marine mammals in the open ocean and at depth: hearing and whistling by two white whales down to 30 atmospheres. Journal of the Acoustical Society of America 101, 3136.

Shibata, K., Fujita, S., Takahashi, H., Yamaguchi, A., Koji, T., 2000. Assessment of decalcifying protocols for detection of specific RNA by non-radioactive in situ hybridization in calcified tissues. Histochemistry and Cell Biology 113, 153-159.

Wever, E.G., McCormick, J.G., Palin, J., Ridgway, S.H., 1971a. Cochlea of dolphin, Tursiops truncatus - general morphology. Proceedings of the National Academy of Sciences of the United States of America 68 (2381-\&).

Wever, E.G., McCormick, J.G., Palin, J., Ridgway, S.H., 1971b. Cochlea of dolphin, Tursiops truncatus.2. Basilar membrane. Proceedings of the National Academy of Sciences of the United States of America 68 (2708-\&).

Wever, E.G., McCormick, J.G., Palin, J., Ridgway, S.H., 1971c. Cochlea of dolphin.3. Tursiops truncatus - hair cells and ganglion cells. Proceedings of the National Academy of Sciences of the United States of America 68 (2908-\&). 